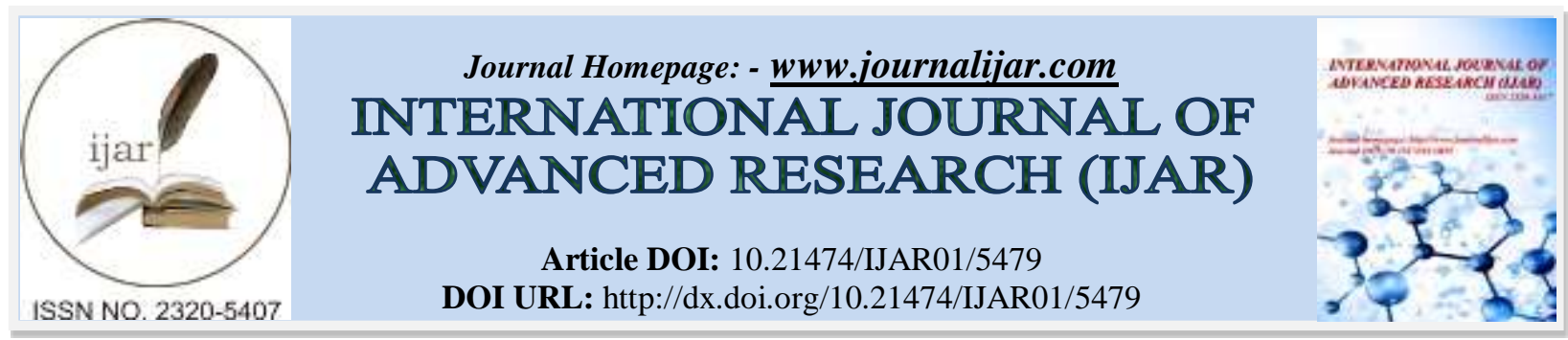

RESEARCH ARTICLE

\title{
THERMODYNAMICAL PROPERTIES OF SODIUM CHLORIDE IN AQUEOUS CETYL TRIMETHYL AMMONIUM BROMIDE SOLUTION USING ULTRASONIC STUDY.
}

\author{
S. Rama Praba, *K. Renuka Devi and M. Mahalakshmi. \\ Department of Physics, Government Arts College for Women (A) Pudukkottai-622 001, Tamilnadu, India.
}

\section{Manuscript Info}

Manuscript History

Received: 20 July 2017

Final Accepted: 22 August 2017

Published: September 2017

Key words:-

$\mathrm{CTAB}, \mathrm{NaCl}$, internal pressure, free volume $\Delta \pi_{\mathrm{i}}$.

\section{Abstract}

The thermodynamical behaviour of sodium chloride in aqueous cetyltrimethyl ammonium bromide (CTAB) solution at 303K, 308K and $313 \mathrm{~K}$ is studied. Density $(\rho)$, viscosity $(\eta)$ and ultrasonic velocities $(\mathrm{U})$ of the solutions are measured experimentally at different concentrations of sodium chloride. For this, aqueous solutions of CTAB are prepared at three molarities $(0.2 \mathrm{mM}, 0.3 \mathrm{mM}$ and $0.4 \mathrm{mM})$. By knowing the experimental values, the internal pressure $\left(\pi_{\mathrm{i}}\right)$ and free volume $\left(\mathrm{V}_{\mathrm{f}}\right)$ of the solutions are determined. From these values quantitative relations between internal pressure, free volume with concentration of these solutions are verified. The results show that sodium chloride existing in aqueous cetyltrimethyl ammonium bromide act as structure-breaker. $\Delta \pi_{\mathrm{i}}, \mathrm{A}, \mathrm{B}$ values of internal pressure, C, D values of free volume and viscosity B-coefficient of Jones-Dole equation are also evaluated to support the present study.

Copy Right, IJAR, 2017,. All rights reserved.

\section{Introduction:-}

Surfactants play an important role as cleaning, wetting, dispersing and emulsifying, foaming and anti-foaming agents in many practical applications. Surfactants are usually organic compounds that are amphiphilic, i.e., they contain both hydrophobic groups (their tails) and hydrophilic groups (their heads). Therefore, a surfactant contains both a water-insoluble component and a water soluble component. Surfactant is a compound that lower the surface tension of a liquid, the interfacial tension between two liquids that between a liquid and soap. Surfactant molecules will migrate to the water surface, where the insoluble hydrophobic group may extend out of the bulk water phase, either in to the air or, in to the oil phase, while the water soluble head group remains in the water phase. This alignment and aggregation of surfactant molecules are at the water/air or water/oil interface. Surfactants are generally classified on the basis of their ionic properties such as anionic, cationic, non-ionic and Zwitterionic surfactants.

Among them, the surfactant chosen for present study is cationic surfactant (CTAB). Cations are formed in reactions where alkyl halides react with primary, secondary, or ternary amines. In this type of surfactant, the water-soluble part of the molecule has a positive charge and the water-insoluble part of the molecule is hydrocarbon, thus giving in the name of a cationic surface active agents. Cetrimonium $\left(\mathrm{C}_{19} \mathrm{H}_{42} \mathrm{BrN}\right)$ or (cetyltrimethyl ammonium bromide) cation is an effective antiseptic agent against bacteria and fungi. It is also one of the main components of the buffer for the extraction of $\mathrm{DNA}^{[1]}$. Detergent fillers are the materials, which are added in detergents to alter their physical

Corresponding Author:- S. Rama Praba.

Address:- Department of Physics, Government Arts College for Women (A) Pudukkottai-622 001,

Tamilnadu, India. 
characteristics and properties. Sodium chloride is one of the important filler used in detergents. It is used as water softening agent, and to standardize their level in the detergent.

Ultrasonic has become the most inspiring and delighting field of scientific research among the researchers. The ultrasonic parameters provide useful information regarding the molecular packing. The observed and calculated thermodynamical parameters are used to explain molecular association, complex formation and solute-solvent interactions. Literature survey shows that ultrasonic velocity, density, viscosity and allied thermodynamic parameters play a key role to study the nature of intermolecular forces in liquid solutions and the physico-chemical behaviour of liquid mixture ${ }^{[2]}$.

In the present work, thermodynamic properties of $\mathrm{CTAB}(0.2 \mathrm{mM}, 0.3 \mathrm{mM}$ and $0.4 \mathrm{mM})$ with $\mathrm{NaCl}$ at different concentrations $(0.1 \mathrm{M}$ to $0.5 \mathrm{M})$ and different temperatures are studied.

\section{Experimental method:-}

Aqueous solutions of CTAB $(0.2 \mathrm{mM}, 0.3 \mathrm{mM}$ and $0.4 \mathrm{mM})$ were prepared and used on the day they were prepared. Solutions of sodium chloride of various concentrations from $0.1 \mathrm{M}$ to $0.5 \mathrm{M}$ are prepared on the molarity concentrations scale using Denver electric digital balance with a precision of $\pm 1 \times 10^{-4} \mathrm{~g}$.

The ultrasonic velocities of the solutions were measured with an accuracy of $\pm 0.5 \%$ using an ultrasonic interferometer (Mittal Enterprises, New Delhi, Model: F-81) with a single crystal operating at a frequency of $2 \mathrm{MHz}$. The density of solutions was measured using a $10 \mathrm{ml}$ specific gravity bottle with an accuracy of $\pm 0.1 \mathrm{Kg} \mathrm{m}^{-3}$. Ostwald's viscometer of $10 \mathrm{ml}$ capacity was used for viscometric studies. The time flow was measured using a racer stop watch with an accuracy of $\pm 0.1 \mathrm{sec}$. A constant temperature bath (RAAGA Industries, Chennai) which could maintain temperature within $\pm 0.1^{\circ} \mathrm{C}$ is used throughout the experiment.

\section{Theory and calculation:-}

Using the measured values of density, viscosity and velocity, the internal pressure and free volume are evaluated using standard formulae.

Internal Pressure $\left(\pi_{i}\right)$ :-

The internal pressure is the cohesive forces, which is the resultant forces of attraction and forces of repulsion between the molecules.

$$
\pi_{i}=b R T\left(\frac{K \eta}{U}\right)^{1 / 2}\left(\frac{\rho^{2 / 3}}{M^{7} / 6}\right) \quad \mathrm{Nm}^{-2}
$$

$\mathrm{b}$ stands for cubic packing, which is assumed to be 2 for all liquids. $\mathrm{K}$ is a dimensional constant independent of temperature and nature of liquids. Its value is $4.281 \times 10^{9}$, T-absolute temperature in Kelvin, M-effective molecular weight, R-universal gas constant, $\eta$-viscosity of solution in $\mathrm{Nsm}^{-2}, \mathrm{U}$-ultrasonic velocity in $\mathrm{ms}^{-1}$ and $\rho$-density of solution in $\mathrm{Kgm}^{-3}$.

Free volume $\left(V_{f}\right)$ :-

Free volume is defined as the average volume in which the centre of the molecules can move inside the hypothetical cell due to the repulsion of surrounding molecules. The dimensional relation given by C.V. Suryanarayana and Kuppusamy ${ }^{[3]}$ which is based on the viscosity and ultrasonic velocity data as,

$$
V_{f}=\left(\frac{M_{e f f} U}{K \eta}\right)^{3 / 2} \quad \mathrm{~m}^{3}
$$

\section{Change in the internal pressure:-}

Change in internal pressure $\left(\Delta \pi_{i}\right)$ is defined as difference between the internal pressure of solvent and solution. Change in internal pressure may be used to interpret the structural behaviour of the solute towards the solvent. Depending upon its sign and nature, the ions can be classified as structure maker and structure breaker.

$$
\Delta \pi_{i}=\pi_{i}-\pi_{0}
$$

Quantitative relationship between internal pressure and free volume dependent on concentration:Suryanarayana C.V and Kuppusami found a relation between internal pressure and free volume at a given temperature of the form 


$$
\pi_{i}=\pi_{0}+A m^{2}+B m
$$

where, $\pi_{0}$ is the internal pressure of the solvent, $\mathrm{m}$ is the molarity, holds good not only for all electrolytes but also with glucose ${ }^{[4]}$. The constants $\mathrm{A}$ and $\mathrm{B}$ are dependent on temperature.

A similar relation holds for the free volume

$$
V_{f}=V_{f(0)}+C m^{2}+D m
$$

Here, $V_{f(0)}$ is the free volume of the solvent. The arbitrary coefficients $\mathrm{C}$ and D are dependent on temperature.

Relation between viscosity and concentration:-

$\mathrm{A}$ and $\mathrm{B}$ coefficients of viscosity for the surfactant solutions were calculated from the Jones-Dole equation ${ }^{[5]}$

$$
\frac{\eta}{\eta_{0}}=1+A m^{2}+B m
$$

where $\eta$ is the viscosity of the solution, $\eta_{0}$ is the viscosity of the solvent and $\mathrm{m}$ is the molar concentration of the solute. A is determined by ionic attraction theory of Falkenhagen-Vernon and therefore called as Falkenhagen coefficient ${ }^{[6]}$, B is Jones-Dole co-efficient is an empirical constants determined by solute-solvent interactions.

\section{Results and discussion:-}

Using the observed values of ultrasonic velocity, viscosity and density, thermodynamical parameters such as internal pressure, free volume, change in internal pressure are calculated and their values are tabulated in table (1) for aqueous $\mathrm{CTAB}(0.2 \mathrm{mM}, 0.3 \mathrm{mM}$ and $0.4 \mathrm{mM})$ with $\mathrm{NaCl}(0.1 \mathrm{M}$ to $0.5 \mathrm{M})$ solutions at $303 \mathrm{~K}, 308 \mathrm{~K}$ and $313 \mathrm{~K}$ respectively.

\section{Internal pressure:-}

The determination of internal pressure is very important in the study of the thermodynamical properties of liquids. Internal pressure is the fundamental property of liquid which provides an excellent basis for examining the solution phenomena and studying various properties of liquid state. It is a measure of change in internal energy of liquid solution as it undergoes a very small isothermal change. It is also a measure of cohesive (or) binding forces between the solute and solvent molecules. The interaction depends upon the solvent and solute structure. It measures the molecular cohesion and the instantaneous volume derivatives of cohesive energy associated with an isothermal expansion of the solution.

It is observed that the values of internal pressure decreases with increasing concentration of $\mathrm{NaCl}$ and also with different concentration of CTAB for $303 \mathrm{~K}$ and $308 \mathrm{~K}$. Internal pressure values decreases with increasing temperature at all concentration of $\mathrm{NaCl}$ and also with $\mathrm{CTAB}$. The decrease of internal pressure may be due to the breaking up of hydrogen bond in the solvent medium and contact ion paring may reduce the association between ion and solvent ${ }^{\text {[7] }}$ (K.Renuka Devi and S.Geetha, et al, 2015). Addition of $\mathrm{NaCl}$ in aqueous CTAB decreases the cohesive forces of the solvent which is the reason for reduction in ion-solvent interaction resulting in lowering of internal pressure at all temperatures and hence it behaves as structure breaker ${ }^{[8]}$ (C.V Suryanarayana, J. Kuppusami, et al, 1981). This is the behaviour of chloride ions in solution. The same behaviour is noted for $0.2,0.3$ and $0.4 \mathrm{mM}$ of CTAB solutions at $303 \mathrm{~K}$ and $308 \mathrm{~K}$. The internal pressure of aqueous solutions of CTAB increases with increasing concentration is observed at $313 \mathrm{~K}$. The increasing concentration of CTAB produces more number of hydrophilic and hydrophobic parts that will increase the cohesive forces of $\mathrm{CTAB}$ towards $\mathrm{NaCl}$ and hence internal pressure increases.

The internal pressure decreases with the rise in temperature because when the temperature is increased, there is a tendency for the ions to move away from each other, reducing the possibility for interaction, which may further reduce the cohesive forces and ultimately leads to decrease in internal pressure ${ }^{[9-10]}$. It is due to the thermal dissociation of some of the solvent molecules from the solvated ions.

\section{Free volume:-}

Free volume is the effective volume in which the centre of a molecule can move when all other molecules are held fixed at their mean positions. The free volume of a solute at a particular temperature and pressure depends only on 
internal pressure of the liquid in which it is immersed. The weakening of molecular association leads to large free volume available for molecular motion and reverse effect gives rise to smaller free volume.

From the table (1), it is observed that the free volume increases with increasing concentration of surfactant CTAB and also with concentration of $\mathrm{NaCl}$ at two temperatures viz., $303 \mathrm{~K}$ and $308 \mathrm{~K}$. Free volume increases with concentration of solute $\mathrm{NaCl}$ and decreases with increasing concentration of aqueous $\mathrm{CTAB}$ at $313 \mathrm{~K}$.

At $313 \mathrm{~K}$, when the solute is added to solvent, the structure of solvent is broken. The available space of solvent in the solution is reduced hence the solution becomes more compressed. So the free volume decreases with rise in concentration of $\mathrm{CTAB}^{[11]}$ (K.Renuka Devi, A.Gomathiyalini, et al., 2016). The decrease in free volume in the system shows that the strength of interaction decreases gradually with the increase in CTAB concentration. The decrease in free volume is due to the presence of tightly packed solvent molecules around the ions at $313 \mathrm{~K}$. This indicates that there is a significant interaction between ions and solvent molecules.

When the temperature rises, the repulsive force between the solute and solvent is more and the free space availability also increases. So, free volume increases with increase in temperature. The increase in free volume and the decrease in internal pressure indicates the existence of strong solute-solvent interaction. Hence, the addition of filler to the surfactant increases the efficiency of CTAB. It is clear from the observations that the cleaning efficiency of surfactant in the presence of $\mathrm{NaCl}$ is mainly depends on concentration of $\mathrm{CTAB}$ and temperature.

\section{Change in internal pressure:-}

Change in internal pressure $\left(\Delta \pi_{i}=\pi_{i}-\pi_{0}\right)$ can be positive or negative depending on the solute added. The validity of the relation is tested for the systems studied. Negative $\Delta \pi_{i}$ denotes that the internal pressure of the solution is lower than that of the solvent. This may be due to the fact that the cohesive forces may get loosened perhaps by breaking hydrogen bonds in water ${ }^{[12]}$ (K.Renuka Devi, S.Rathika et al., 2015). It is observed that the $\Delta \pi_{i}$ values decrease with increasing concentrations of $\mathrm{NaCl}$ and $\mathrm{CTAB}$ is noted at all temperatures. It is found by observation that the $\Delta \pi_{i}$ value is found to be negative for all temperatures and concentration of solution and it reveals that the filler $\mathrm{NaCl}$ act as a structure breaker. This may be due to the structure breaking nature $\mathrm{NaCl}$.

\section{Relationship between internal pressure and free volume with concentration:-}

The internal pressure and free volume constants A, B, C and D were evaluated by least square method. The values of internal pressure constants $\mathrm{A}$ and $\mathrm{B}$ are used to confirm the structural behaviour of surfactant molecules. Coefficient A refers to the attractive component and B to the repulsive component.

In this system, the sign and magnitude of internal pressure B is negative in concurrence with the $\Delta \pi_{i}$ values. Thus, the effect of repulsive forces or cohesive forces in ion-solvent interactions is very well under stood by $\Delta \pi_{i}$. B is found to be negative at all concentration of CTAB at all temperatures and hence, $\Delta \pi_{i}$ is negative indicating that the internal pressure of solution decreases due to the addition of sodium chloride which confirms that $\mathrm{NaCl}$ acts as a structure breaker. The free volume of the solution increases with increasing concentration.

The co-efficient $\mathrm{A}$ values found to be negative at all concentration of the surfactant solution and also with temperatures. The free volume constants $\mathrm{C}$ and $\mathrm{D}$ values show the exactly reverse trend as that of $\mathrm{A}$ and $\mathrm{B}$ in magnitude and sign.

Figure (7 to 10) shows the temperature dependent of A, B, C and D for surfactant solutions studied. A versus temperature curve shows a minimum at $308 \mathrm{~K}$ for $0.2 \mathrm{mM}$ and $0.3 \mathrm{mM}$ CTAB. In $0.4 \mathrm{mM} \mathrm{CTAB}$, the curve increases with increasing temperature is noted. Variation of $\mathrm{B}$ with temperature is shown in fig (9). It is reverse to the variation of $A$ at the all concentration of CTAB. In the case of $0.2 \mathrm{mM}$ and $0.3 \mathrm{mM}$ CTAB solutions, $C$ values are maximum at $308 \mathrm{~K}$. For $0.4 \mathrm{mM} \mathrm{CTAB}$, it decreases with increase in temperature. The values of $\mathrm{D}$ are reverse as that of $\mathrm{C}$ values for all concentration of CTAB. From this observation, it is clear that variation of $\mathrm{C}$ is reverse trend to that of $\mathrm{A}, \mathrm{D}$ is reverse to that of $\mathrm{B}$ values.

\section{Relation between viscosity with concentration:-}

In order to shed more light on this, the role of viscosity B-coefficient has also been obtained. The values of the Bcoefficient represent the solute-solvent interaction and a measure of order or disorder introduced by the solute into the solvent structure ${ }^{[13]}$. It is also a measure of solute-solvent interaction and the relative size of the solute and 
solvent molecules. From the table (2), it is observed that the values of A are positive for all concentration of CTAB and $\mathrm{B}$-coefficients are negative for $0.2 \mathrm{mM} \mathrm{CTAB}$ and positive for remaining concentration of CTAB except at $0.3 \mathrm{mM}$, where the values are negative at $313 \mathrm{~K}$. Since, A is a measure of ionic interaction. It is evident that there is a strong ion-ion interaction in the aqueous CTAB solution is studied, which is indicated by the higher magnitude of A values. The negative value of $\mathrm{B}$ is indicative of weak solute-solvent interaction. The magnitude of B clearly confirms that the $\mathrm{NaCl}$ is acting as an effective structure-breaker in aqueous CTAB solution at $0.2 \mathrm{mM}^{[14]}$ (Sumathi $\mathrm{T}$ and Varalakshmi M, et al, 2010). Whereas, the positive values of B is indicative of strong ion-solvent interactions owing to the structure-making tendency of the CTAB molecules.

The temperature dependent of viscosity A and B-coefficients for surfactant solutions are shown in fig (11\&12). A versus temperature curves show a minimum at $308 \mathrm{~K}$ for $0.2 \mathrm{mM}$ and $0.3 \mathrm{mM} \mathrm{CTAB}$, but in $0.4 \mathrm{mM}$ solutions the value of A increases with temperature is noted. Variation of $\mathrm{B}$ with temperature is similar to the internal pressure $\mathrm{B}$ coefficient and reverse trend to the viscosity A with temperature.

Table 1:- Values of internal Pressure, free volume and change in internal pressure of aqueous solution of CTAB $(0.2 \mathrm{mM}$ to $0.4 \mathrm{mM})$ with filler $\mathrm{NaCl}$

\begin{tabular}{|c|c|c|c|c|c|c|c|c|c|}
\hline \multirow[t]{2}{*}{$\begin{array}{l}\text { Molarity } \\
\text { (M) }\end{array}$} & \multicolumn{3}{|c|}{$\begin{array}{c}\text { Internal Pressure } \\
\qquad 10^{8} \mathrm{~N} / \mathrm{m}^{2}\end{array}$} & \multicolumn{3}{|c|}{$\begin{array}{l}\text { Free volume }\left(\mathrm{V}_{\mathrm{f}}\right) \\
10^{-8} \mathrm{~m}^{3}\end{array}$} & \multicolumn{3}{|c|}{$\Delta \pi_{i}$} \\
\hline & $303 \mathrm{~K}$ & $308 \mathrm{~K}$ & $313 \mathrm{~K}$ & $303 \mathrm{~K}$ & $308 \mathrm{~K}$ & $313 \mathrm{~K}$ & $303 \mathrm{~K}$ & $308 \mathrm{~K}$ & $313 \mathrm{~K}$ \\
\hline \multicolumn{10}{|c|}{$0.2 \mathrm{mM} \mathrm{CTAB}$ with $\mathrm{NaCl}$} \\
\hline 0 & 25.9477 & 24.9315 & 23.9204 & 2.2446 & 2.6426 & 3.1231 & 0.1055 & 0.0747 & -0.0050 \\
\hline 0.1 & 25.2880 & 24.3747 & 23.3400 & 2.3197 & 2.7182 & 3.2184 & -0.6597 & -0.5567 & -0.5803 \\
\hline 0.2 & 24.5203 & 23.5800 & 22.5225 & 2.4036 & 2.8337 & 3.3751 & -1.4273 & -1.3515 & -1.3978 \\
\hline 0.3 & 23.6866 & 22.8432 & 21.8106 & 2.5152 & 2.9347 & 3.5114 & -2.2610 & -2.0882 & -2.1097 \\
\hline 0.4 & 22.9426 & 22.1118 & 21.1732 & 2.6188 & 3.0580 & 3.6413 & -3.0050 & -2.8196 & -2.7471 \\
\hline 0.5 & 22.4320 & 21.6145 & 20.6120 & 2.7023 & 3.1417 & 3.7723 & -3.5157 & -3.3169 & -3.3083 \\
\hline \multicolumn{10}{|c|}{$0.3 \mathrm{mM}$ CTAB with $\mathrm{NaCl}$} \\
\hline 0 & 25.8965 & 24.9108 & 24.0180 & 2.2608 & 2.6615 & 3.1061 & 0.0543 & 0.0540 & 0.0925 \\
\hline 0.1 & 25.2744 & 24.3653 & 23.4655 & 2.3290 & 2.7280 & 3.2004 & -0.6220 & -0.5454 & -0.5524 \\
\hline 0.2 & 24.4193 & 23.5792 & 22.6574 & 2.4372 & 2.8373 & 3.3500 & -1.4771 & -1.3315 & -1.3605 \\
\hline 0.3 & 23.6289 & 22.8145 & 21.9199 & 2.5422 & 2.9510 & 3.4890 & -2.2675 & -2.0962 & -2.0980 \\
\hline 0.4 & 22.8630 & 22.1011 & 21.2157 & 2.6473 & 3.0688 & 3.6337 & -3.0334 & -2.8096 & -2.8022 \\
\hline 0.5 & 22.3766 & 21.5663 & 20.7158 & 2.7259 & 3.1730 & 3.7475 & -3.5198 & -3.3444 & -3.3021 \\
\hline \multicolumn{10}{|c|}{$0.4 \mathrm{mM}$ CTAB with $\mathrm{NaCl}$} \\
\hline 0 & 25.8116 & 24.8977 & 24.0502 & 2.2872 & 2.6699 & 3.1017 & -0.0305 & 0.0409 & 0.1247 \\
\hline 0.1 & 25.2397 & 24.3474 & 23.5031 & 2.3455 & 2.7399 & 3.1906 & -0.5718 & -0.5502 & -0.5470 \\
\hline 0.2 & 24.3741 & 23.5690 & 22.6915 & 2.4525 & 2.8426 & 3.3357 & -1.4375 & -1.3286 & -1.3586 \\
\hline 0.3 & 23.5699 & 22.7731 & 21.9383 & 2.5670 & 2.9677 & 3.4824 & -2.2416 & -2.1245 & -2.1118 \\
\hline 0.4 & 22.7899 & 22.0502 & 21.2330 & 2.6820 & 3.0911 & 3.6259 & -3.0216 & -2.8475 & -2.8171 \\
\hline 0.5 & 22.2921 & 21.5511 & 20.7808 & 2.7599 & 3.1878 & 3.7260 & -3.5194 & -3.3465 & -3.2693 \\
\hline
\end{tabular}

Table 2:- Values of internal pressure $A \& B$ coefficient and free volume $C \& D$ coefficient and viscosity $A \& B$ coefficient Jones-Dole equation of aqueous CTAB solutions with filler $\mathrm{NaCl}$

\begin{tabular}{|c|c|c|c|c|c|c|c|}
\hline \multirow{2}{*}{$\begin{array}{l}\text { Molarity } \\
\text { (M) }\end{array}$} & \multirow{2}{*}{$\begin{array}{l}\text { Temperature } \\
(\mathrm{K})\end{array}$} & \multicolumn{2}{|c|}{$\begin{array}{l}\text { Internal pressure }\left(\pi_{\mathrm{i}}\right) \\
\mathrm{N} / \mathrm{m}^{2}\end{array}$} & \multicolumn{2}{|c|}{$\begin{array}{l}\text { Free volume } \\
\mathrm{m}^{3}\end{array}$} & \multicolumn{2}{|c|}{$\begin{array}{l}\text { Viscosity } \\
\operatorname{Nsm}^{-2}\end{array}$} \\
\hline & & $\begin{array}{l}\text { Constant } \\
\text { A } 10^{9}\end{array}$ & $\begin{array}{l}\text { Constant } \\
\text { B } 10^{9}\end{array}$ & Constant $\mathrm{C} 10^{-8}$ & $\begin{array}{l}\text { Constant } \\
\text { D } 10^{-8}\end{array}$ & $\begin{array}{c}\text { Constant } \\
\text { A }\end{array}$ & $\begin{array}{c}\text { Constant } \\
\text { B }\end{array}$ \\
\hline \multirow{3}{*}{$0.2 \mathrm{mM}$} & 303 & -0.1238 & -0.6791 & 0.4675 & 0.7740 & 0.1244 & -0.0266 \\
\hline & 308 & -0.2426 & -0.5865 & 0.7251 & 0.7197 & 0.1158 & -0.0203 \\
\hline & 313 & -0.1500 & -0.6212 & 0.5676 & 1.0027 & 0.1517 & -0.0291 \\
\hline \multirow[b]{2}{*}{$0.3 \mathrm{mM}$} & 303 & -0.1836 & -0.6606 & 0.6454 & 0.6924 & 0.0977 & 0.0059 \\
\hline & 308 & $\begin{array}{l}-0.2831 \\
\end{array}$ & -0.5713 & 0.8540 & 0.6539 & 0.0645 & 0.0230 \\
\hline
\end{tabular}




\begin{tabular}{|c|c|c|c|c|c|c|c|c|c|}
\hline & 313 & -0.2368 & -0.5876 & & 0.7789 & & 0.9745 & 0.0690 & -0.0109 \\
\hline \multirow{3}{*}{$0.4 \mathrm{mM}$} & 303 & -0.3007 & -0.5609 & & 0.8861 & & 0.5890 & 0.0435 & 0.0147 \\
\hline & 308 & -0.2853 & -0.5751 & & 0.8606 & & 0.6708 & 0.0667 & 0.0079 \\
\hline & 313 & \multicolumn{2}{|c|}{-0.2385} & -0.5861 & 0.8589 & 0.9197 & 0.0759 & 0.0051 & \\
\hline
\end{tabular}

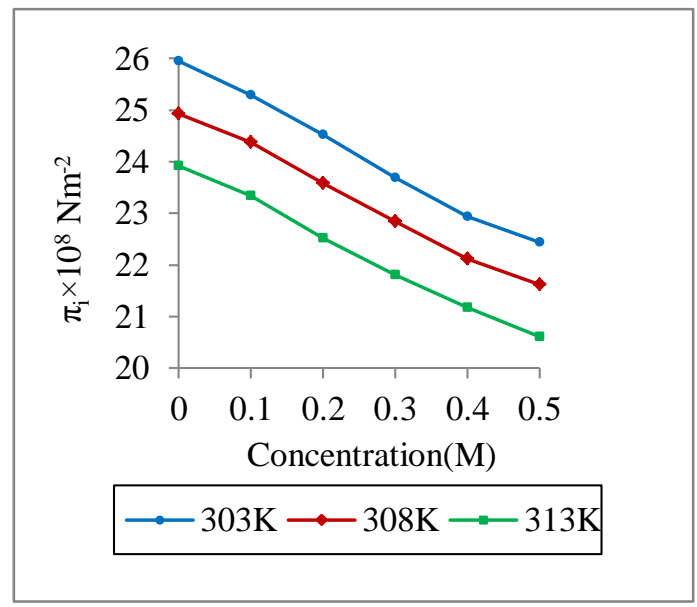

Fig1:-Variation of internal pressure of $\mathrm{NaCl}$ with $0.2 \mathrm{mM} \mathrm{CTAB}$ at different temperatures

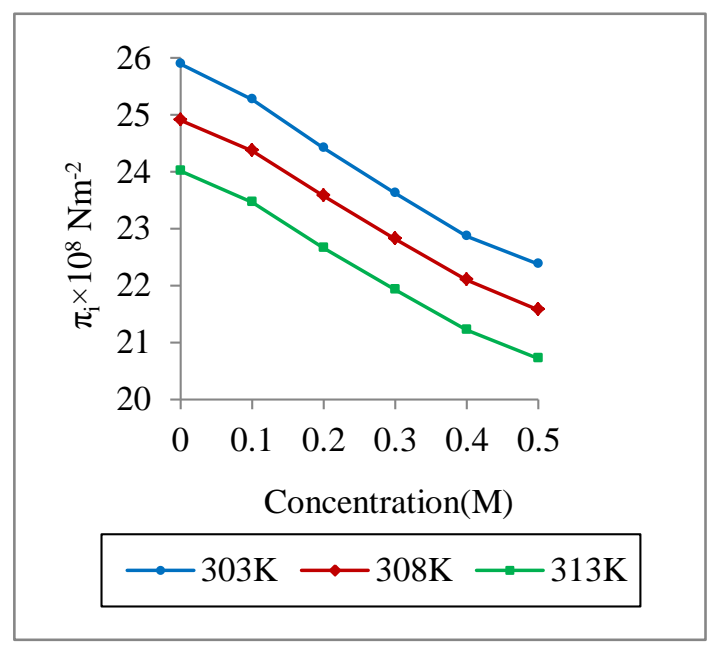

Fig 2:- Variation of internal pressure of $\mathrm{NaCl}$ with $0.3 \mathrm{mM}$ CTAB at different temperatures

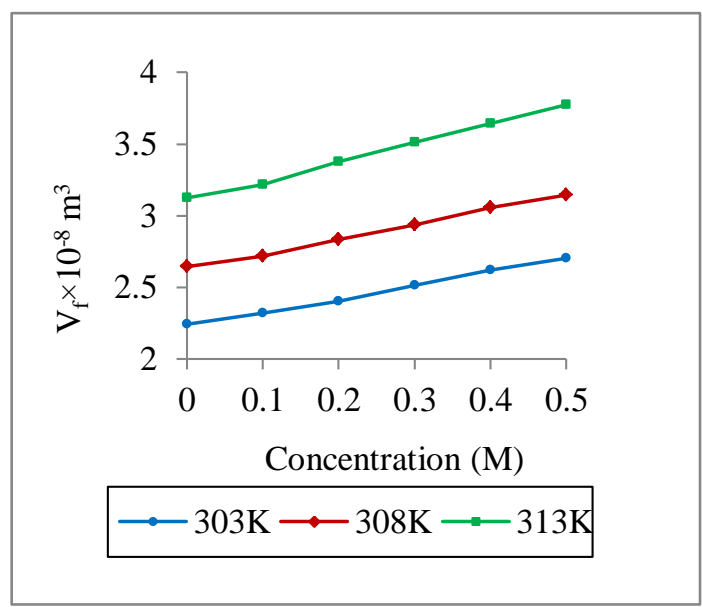

Fig 4:- Variation of free volume of $\mathrm{NaCl}$ with $0.2 \mathrm{mM}$ CTAB at different temperatures

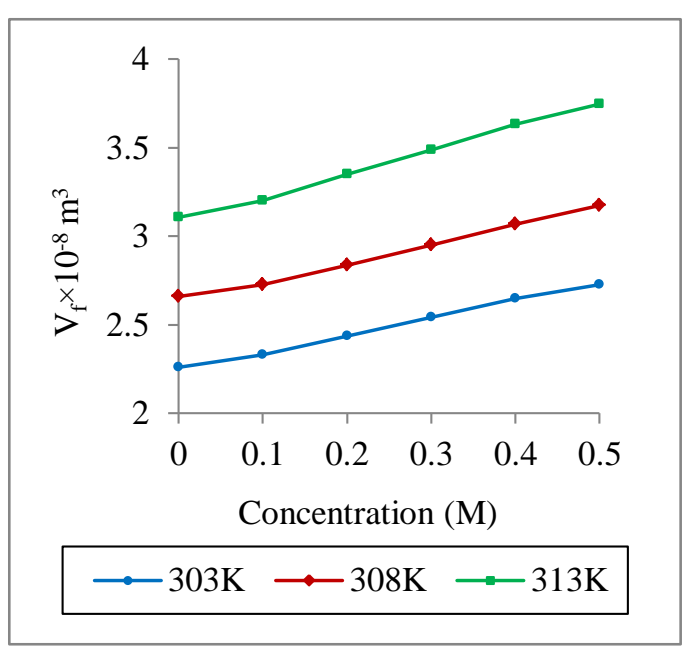

Fig 5:- Variation of free volume of $\mathrm{NaCl}$ with $0.3 \mathrm{mM} \mathrm{CTAB}$ at different temperatures 


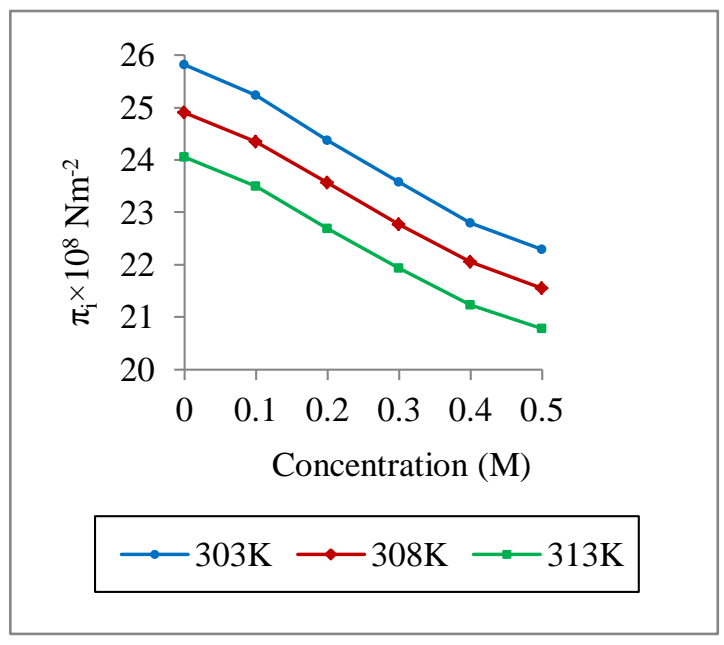

Fig 3:- Variation of internal pressure of $\mathrm{NaCl}$ with $0.4 \mathrm{mM} \mathrm{CTAB}$ at different temperatures

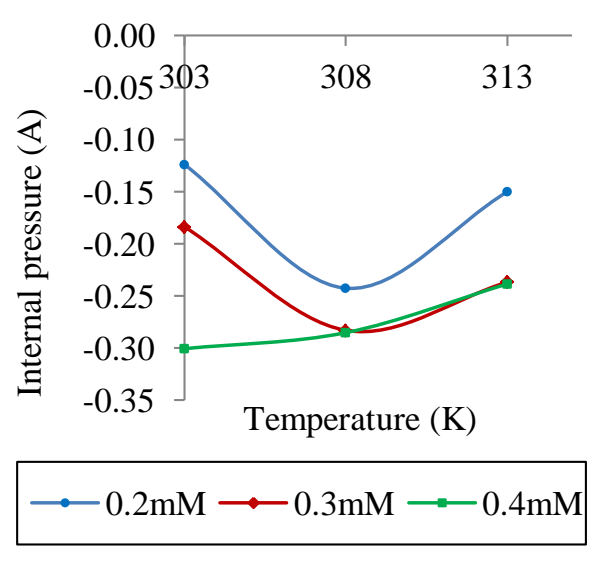

Fig 7:- Variation of A with temperature

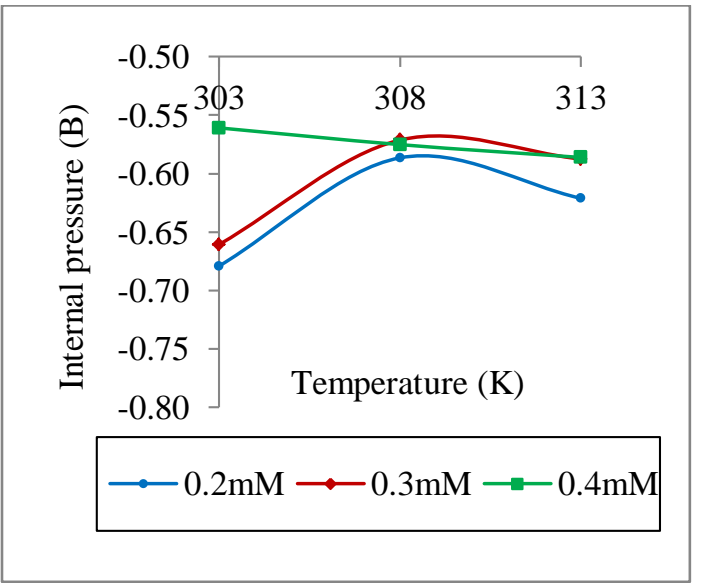

Fig 9:-Variation of B with temperature

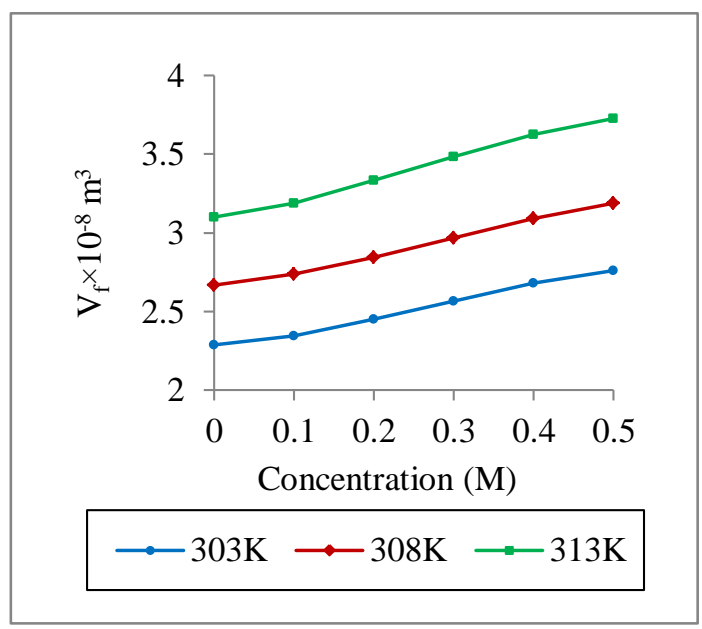

Fig 6:-Variation of free volume of $\mathrm{NaCl}$ with $0.4 \mathrm{mM} \mathrm{CTAB}$ at different temperatures

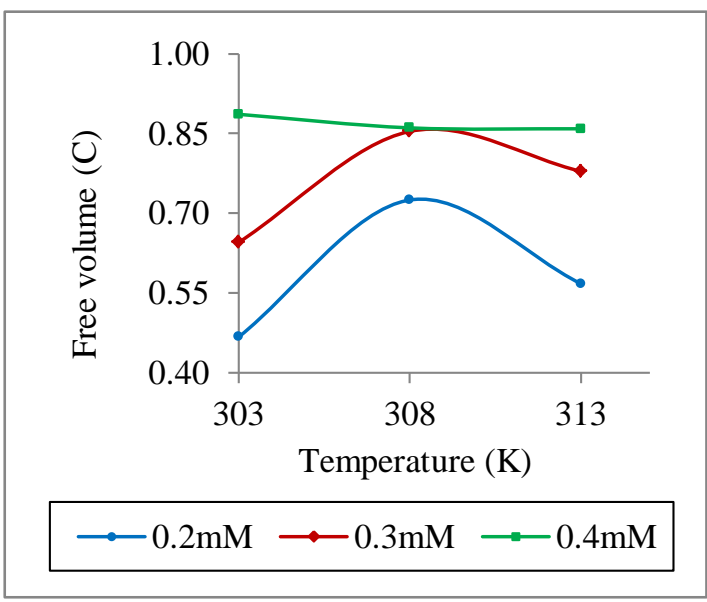

Fig 8:-Variation of $\mathrm{C}$ with temperature

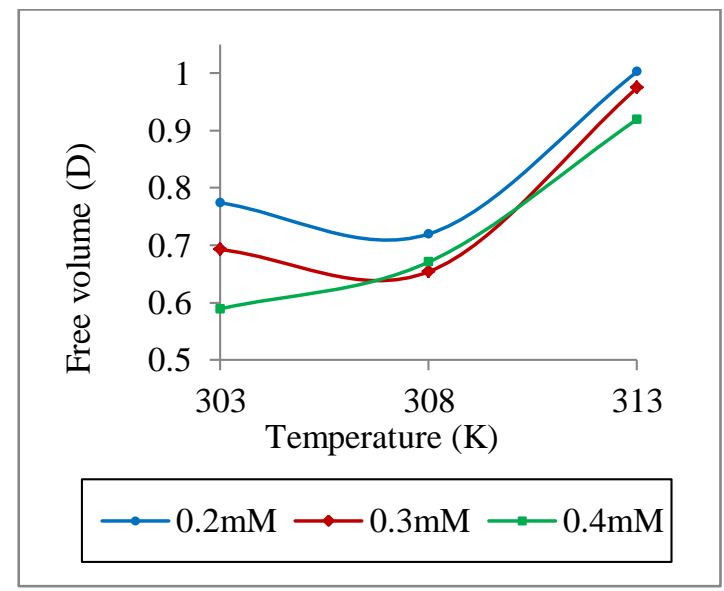

Fig 10:-Variation of $\mathrm{D}$ with temperature 


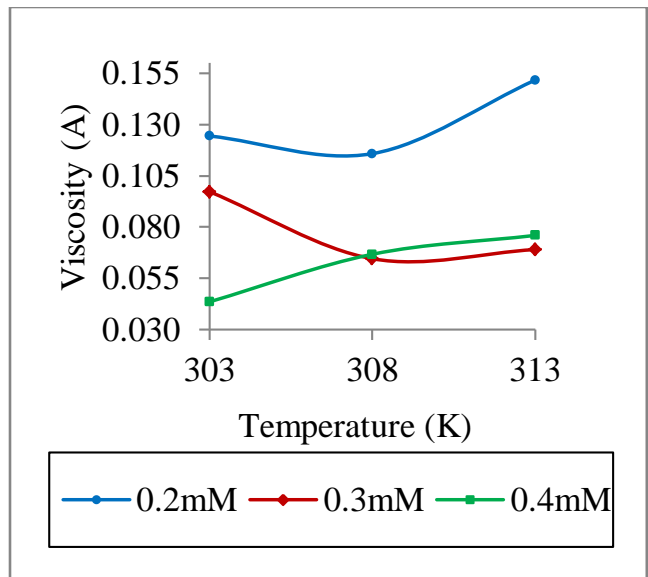

Fig 11:- Variation of viscosity (A) with tremperatures

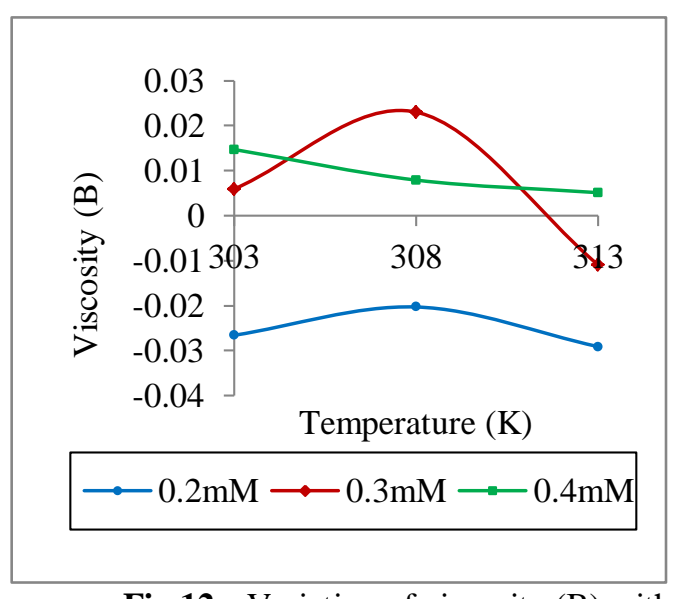

Fig 12:- Variation of viscosity (B) with temperatures

\section{Conclusion:-}

Ultrasonic investigations of aqueous $\mathrm{CTAB}$ with various concentrations of $\mathrm{NaCl}$ have been studied. The observed data and variations of thermodynamical parameters with molar concentration of $\mathrm{NaCl}$ in aqueous surfactant provide useful information about the nature of intermolecular interactions existing in the solutions. Addition of $\mathrm{NaCl}$ in aqueous $\mathrm{CTAB}$ decreases the cohesive forces resulting in lowering of internal pressure at all temperatures and hence it behaves as structure breaker. Free volume is an inverse function of $\pi_{i}$. The internal pressure B co-efficient is found to be negative in concurrence with the $\Delta \pi_{i}$ values. The negative values of $\mathrm{B}$ co-efficient confirm the structure breaking nature of $\mathrm{NaCl}$ in $\mathrm{CTAB}$. In comparing different concentration of CTAB $(0.2 \mathrm{mM}, 0.3 \mathrm{mM}$ and $0.4 \mathrm{mM})$, it is found that $\Delta \pi_{i}$, internal pressure $\mathrm{B}$ co-efficient and viscosity $\mathrm{B}$ co-efficient are found to be negative. This investigation suggests that the structure-breaking nature of $\mathrm{NaCl}$ in the bulk of solvent molecules is noted at lower concentration of $0.2 \mathrm{mM} \mathrm{CTAB}$. This leads to the conclusion that $\mathrm{NaCl}$ behaves like effective filler at that concentration. It works efficiently and removes strains from clothes.

\section{References:-}

1. Clarke. and Joseph, D. (2009): Cetyltrimethyl Ammonium Bromide (CTAB) DNA Miniprep for Plant DNA Isolation.

2. Dudhe, C.M. and Patil, K.C. (2012): International Journal of Pharmacy and Pharmaceutical Science Research, 2(4):76-78.

3. Suryanarayana, C.V. and Kuppusamy, J. (1976): J. Acoust. Soc. Ind., 4:75.

4. Ph.D thesis: Gandhimathi, R. (2001): Ultrasonic and thermodynamic study of Electrolytes in aqueous and alcoholic media and study of NMR proton chemical shift of electrolytes.

5. Jones, G. and Dole. (1929): M. J. Am. Chem. Soc., 51: 2950.

6. Flakenhagen, H. and Vernan, E.L. (1932): Z. Phys., 33:140.

7. Renuka Devi, K. and Geetha, S. (2015): Ultrasonic analysis of intermolecular interaction through internal pressure and free volume of aqueous fertilizer solutions, International Journal of Chem Tech Research, 8(11):519-526.

8. Suryanarayana, C.V. and Kuppusami, J. (1981): Role of internal pressure in the chemistry of electrolyte solutions, Journal of Acoustical Soec. of India, Vol. IX (1):4.

9. Kalyansundaram, S., Manuel Stephan, A. and Gopalan, A. (1995): Polym J. Mater. R., 323-333.

10. Jasmine Vasantha Rani, E. and Padmavathy, R. et.al. (2002): Journal of Acoustical Society of India Vol. XXX, 253259.

11. Renuka Devi, K. and Gomathiyalini, A. (2016): Thermodynamical Investigation of Aqueous sodium Dodecyl Sulphate: Comparison of the Fillers Sodium Chloride and Sodium Sulphate, Journal of Chemical and Pharmaceutical Research, 7(11):706-714.

12. Renuka Devi, K. and Rathika, S. (2015): Internal pressure, free volume of aqueous urea solutions at different temperatures, Journal of Chemical and Pharmaceutical Research, 7(8): 967-974.

13. Samanta, T. and Saharay, S.K. (2010): J. Chem. Thermodynamics, 42:1131.

14. Sumathi, T. and Varalakshmi, M. (2010): Ultrasonic velocity, Density and Viscosity Measurement of Methionine in Aqueous Electrolytic Solutions at 303K, Rasayan J. Chem., 3(3):550-555. 